\title{
Natural nanomaterial could be boon to economy of rural Pakistan
}

\section{J.S. Nirwan}

S. Farhaj

M. M. Chaudhary

Z. Khize

S. S. Hasan

A. Angelis-Dimakis

A. Gill

H. Rasheed

N. Abbas

M. S. Arshad

T. Hussain

Y. Shahzad

A. M. Yousaf

T.A. Chohan

T. Hussain

H.A. Merchant

M. R. Akram

T. M. Khan

M. Ashraf

B. R. Conway

M. U. Ghori

\section{Video Abstract}

Keywords: Scientific Reports, montmorillonite clay, nanomaterial, aluminum oxide, silica, Punjab, Pakistan, granulometric purification, large-scale purification, Koh-e-Suleiman mountain range

Posted Date: June 16th, 2020

DOI: https://doi.org/10.21203/rs.3.rs-35884/v1

License: (c) (i) This work is licensed under a Creative Commons Attribution 4.0 International License. Read Full License 


\section{Abstract}

Montmorillonite clay is an abundant and versatile natural nanomaterial. Formed of aluminum oxide sheets sandwiched between layers of silica, montmorillonite is prized for its tremendous absorption and antimicrobial properties, including by those in the pharmaceutical, cosmetics, and water purification industries. Some scientists even believe that the mineral was crucial to catalyzing the primordial reactions that gave rise to the first life forms on earth. Now, a recent study suggests that the same mineral could help breathe life into the economy of rural parts of Pakistan. Montmorillonite deposits are found all over the world, most notably in the Himalayan, Caucasus, and Andes mountains. But an abundant supply of raw clay also exists in the largely untouched mountains found in South Punjab in Pakistan. Here, heavy reliance on agriculture and low levels of industrialization have contributed to higher levels of poverty and unemployment compared with the rest of Punjab. Hoping to unlock the economic potential of montmorillonite in this region, the authors of the recent study devised a sustainable process for readying the mineral for industrial use. The process begins with grinding the raw clay in a ball mall for about 1 hour. The team arrived at that number after testing durations ranging from 20 to 80 minutes. Grinding for any less than 1 hour tended to leave chunks of impurities like quartz among particles of pure montmorillonite. Grinding for any more produced ultrafine particles that tended to cluster with other minerals in solution. Scaling up the purification process proved more than viable. Compared with the small-batch process, large-scale purification produced no significant differences in purity or stability. The only factors altered by scaling up were the amount of mineral generated and the cost of purification. A simple analysis revealed that the cost of purification was governed by two factors: the cost of electricity needed to grind raw montmorillonite and the purification yield. While a longer grind time tended to become increasingly expensive, at the optimal yield point, 1 hour, the amount of pure mineral generated offset the cost of grinding. Ultimately, the team estimated that producing $1 \mathrm{gram}$ of montmorillonite should cost approximately one hundredth of a pound, or about 1.9 Pakistani rupees. Given the abundance of montmorillonite in South Punjab, that figure could be highly favorable for those living in the area. This substantial, untapped resource could attract the attention of the multiple industries that use montmorillonite in mass quantities. That, the team hopes, could translate to a wealth of employment opportunities that could greatly improve the economic condition of the region. 